\title{
Estimation the Effective Dose for Pediatric during Common Computed Tomography Exanimations
}

\author{
Momen Alkhair $^{1 *}$, Abdallah I. A. Mohamed ${ }^{2}$, Amel S. A. Elgadal ${ }^{2}$, Suhaib Alameen $^{2}$
}

${ }^{1}$ Sebha University, Faculty of Medical Technology, Morzoque - Libya

${ }^{2}$ Sudan Universities of Science and Technology, College of Medical Radiologic Science, P.O. Box 1908, Khartoum, Sudan

DOI: $10.36347 /$ sjams.2020.v08i06.011

| Received: 19.05.2020 | Accepted: 27.05.2020 | Published: 13.06.2020

*Corresponding author: Momen Alkhair

Abstract

Original Research Article

The aim of this study to estimate the effective dose for pediatric during common Computed Tomography exanimations, at five different hospitals in Khartoum state - Sudan, is presented, the gender distributed according to selected CT scan were the total number of patients was 855 patients, approximately $45 \%$ of the patient for brain (386; 233 males and 153 female), about $22 \%$ for chest (191; 121 males and 70 female), about $10 \%$ for CT abdomen (90; 44 males and 46 female) and $21 \%$ for pelvis CT (188; 102 males and 86 female) with total number of male and female 500 and 355 respectively. The effective dose found $1.93 \mathrm{mSv}$ for brain ( $1.98 \mathrm{mSv}$ for male and $1.87 \mathrm{mSv}$ for female), in CT Chest the effective dose was $3.58 \mathrm{mSv}$ ( $3.57 \mathrm{mSv}$ for male and $3.59 \mathrm{mSv}$ for female), for abdomen was 5.69 $\mathrm{mSv}(5.25 \mathrm{mSv}$ for male and $6.13 \mathrm{mSv}$ for female) and for pelvis the E found $7.14 \mathrm{mSv}(8.04 \mathrm{mSv}$ for male and 6.23 $\mathrm{mSv}$ for female). This study recommends that the CT technologist should be aware to achieving the optimization of patient's dose using the best strategies available for reducing radiation dose, and the patient's Dose must be monitored regularly.

Keywords: MDCT, Effective Dose, Pediatric dose.

Copyright @ 2020: This is an open-access article distributed under the terms of the Creative Commons Attribution license which permits unrestricted use, distribution, and reproduction in any medium for non-commercial use (NonCommercial, or CC-BY-NC) provided the original author and source are credited.

\section{INTRODUCTION}

The computed tomography (CT) is the best technology that gives high-resolution anatomical images of patients. CT images represent transverse slices, which are obtained by an X-ray tube rotating around the human body, today with increasing attention surrounding computed tomography (CT) from radiologic society and the public, with more accurate dose information becomes available for many studies, and to estimate the biological effect from CT procedures [1,2]. Expose to X-ray from CT resulting in high dose to surface of the tissues due to the scattering effect, therefore, the beam divergence and limited collimator efficiency [3], and cancer can be induced CT Exposure according to UNSCEAR. As proved that the patients dose from CT procedures is higher than doses from other x-ray imaging modalities; Such as examined by CT of chest give a higher dose that delivers from conventional chest X-ray reach up to 400 times [4,5]. Recently, studies in CT dosimetry increased, so worries concerning the knowledge have been increased in various usage of CT [6].

Marked improvements in diagnostic imaging performance of CT have been accompanied by increased concern regarding higher radiation doses and corresponding patient risks [7-9].

Radiation doses in CT are markedly higher than in conventional radiography. A chest CT, for example, has an eff ective dose (E) of approximately 5 $\mathrm{mSv}$, which is equivalent to approximately 100 chest radiographic examinations because the latter have eff ective doses of approximately $0.05 \mathrm{mSv}[10]$. Radiation dose quantities in CT are currently expressed in CT dose index (CTDI). [11] Converting CTDI dose indices into meaningful dose metrics (ie, organ and eff ective dose) requires explicit consideration of both technical and patient factors. [12] Converting organ doses into radiation risk data also requires considerable care and must take into account patient demographics $[13,14]$. Quantifying patient detriment needs to take into account the life expectancies of the exposed population and the lengthy latent period associated with radiation-induced cancers [15]. The dose characteristics of new MDCT scanners merit investigation to give practitioners a better Understanding of how radiation doses from these newer systems compare with the single-detector systems prevalent in the 1990s. A major effort has recently been undertaken to optimize CT $[16,17]$ using imaging protocols that explicitly take into 
account the characteristics of the patient being examined [18-20]. It is therefore of interest to investigate how the introduction of MDCT scanners and patient-size-dependent imaging protocols have affected patient doses.

The first role in the principle of radiation protection for medical imaging is the need to balance between the benefit and risk of any patient exposure which called justification [21]. so, it is essential that, the technologist should understand the radiation risks associated with radiological examinations, and the relation between these risks and the patient's information gender and age [22,23]. The main concerning is then due to the significant radiation dose delivered to the radiosensitive organs, thyroid, eye lens and breast because they will be irradiated during radiological procedures of the cervical spine, head and chest [24-26].

The effective dose is a radiation descriptor that may be used to characterize radiation exposures to patients undergoing computed tomographic (CT) examinations, where radiation levels are well below threshold doses required to induce deterministic effects. (The effective dose $E$, defined in publication 60 of the International Commission on Radiological Protection [27], and the effective dose equivalent $H$, defined in publication 26 of the International Commission of Radiological Protection [28], are conceptually identical but use different organ-weighting factors; $E$ and $H_{\mathrm{E}}$ are interchangeable in this article.) The magnitude of the effective dose is related to the stochastic radiation risks of cancer induction and the production of genetic effects.

National and international organizations are using the effective dose to quantify exposures of patients to radiation in diagnostic radiology [29,30]. The aim of the study is to estimate the pediatric radiation dose during Computed Tomography Procedures.

\section{METHODOLOGY}

For a given patient and a constant $\mathrm{x}$-ray tube potential, the value of the effective dose from brain, chest, abdominal and pelvis CT examination depends on the tube current (in milliamperes), the scanning time (in seconds), the section thickness (T), and the total number of sections $(\mathrm{N})$. These four factors were obtained for 855 randomly selected patient's underwnt CT examinations on CT scanners (3 machine Toshiba Aquilion 64 slices, Siemens Sensation 16 slices and GE 16slices).

\section{CT machines}

CT scanners that participated in this study are helical CT scanners in five hospitals. All scanners displayed volume Computed Tomography Dose Index (CTDI) and Dose Length Product (DLP). The data were collected from each CT scanner. All quality control tests were performed to the machines prior to any data collection. All the data were within an accept.

\section{CT dose measurements}

Radiation dose indicators CTDIvol and DLP can be obtained from a dose summary page, which includes information about the CT exam. CTDIvol does allow the comparison of scan protocols or scanners and is useful for obtaining benchmark data to compare techniques, but it's not so good for estimating patient dose [31]. DLP, an indicator of the dose imparted to the patient, is calculated by multiplying CTDIvol times the scan length. In addition to being affected by the issues associated with CTDIvol, DLP can be problematic in a limited scan range [32].

\section{Calculation of Effective Dose}

CT scanners record the radiation exposure as a DLP in mGy.cm. The determination of external exposure to the patient is basically from the CT scan that generates the $\mathrm{x}$-ray. As referred to ICRP publication 102 [33], external exposure will determine using the CT Dose Index (CTDI) and Dose Length Product (DLP) value which can have obtained direct from screen computer scan. The effective dose, E for external exposure was then calculated according to equation [33].

$$
\mathrm{E}=\mathrm{k} \times \mathrm{DLP}
$$

Where $\mathrm{k}$ is coefficient based on empirical weighting factor, which functional of the anatomical region scanned (mSv.mGy-1.cm-1) in ICRP 102 [33] and $\mathrm{k}=0.015$ for trunk.

\section{RESULTS AND DISCUSSION}

An overview of patient information and scan parameters used for Computed Tomography CT At five different hospitals in Khartoum state - Sudan, is presented, the gender distributed according to selected CT scan were the total number of patients was 855 patients, approximately $45 \%$ of the patient for brain (386; 233 males and 153 female), about $22 \%$ for chest (191; 121 males and 70 female), about $10 \%$ for CT abdomen (90; 44 males and 46 female) and $21 \%$ for pelvis CT (188; 102 males and 86 female) with total number of male and female 500 and 355 respectively. 
Table-1: Show the gender distributed according to selected scan

\begin{tabular}{|c|c|c|c|c|c|}
\hline Gender & Brain & Chest & Abdomen & Pelvis & Total \\
\hline Male & 233 & 121 & 44 & 102 & 500 \\
\hline Female & 153 & 70 & 46 & 86 & 355 \\
\hline Total & 386 & 191 & 90 & 188 & 855 \\
\hline
\end{tabular}

Table-2: Show demographic information for all patients

\begin{tabular}{|c|c|c|c|c|}
\hline Exam & Gender & Age years & High cm & Weight kg \\
\hline \multirow[t]{2}{*}{ Brain } & Male & $\begin{array}{c}8.7 \pm 5.5 \\
1-18\end{array}$ & $\begin{array}{c}119.9 \pm 38.7 \\
15-188\end{array}$ & $\begin{array}{c}30.35 \pm 19.2 \\
3-80\end{array}$ \\
\hline & Female & $\begin{array}{c}9.2 \pm 5.6 \\
1-18 \\
\end{array}$ & $\begin{array}{c}121.7 \pm 37.2 \\
20-170\end{array}$ & $\begin{array}{c}31.2 \pm 17.8 \\
5-73\end{array}$ \\
\hline \multirow[t]{2}{*}{ Chest } & Male & $\begin{array}{c}10.8 \pm 6.8 \\
1-18\end{array}$ & $\begin{array}{c}135.15 \pm 40.9 \\
53-180\end{array}$ & $\begin{array}{c}42.5 \pm 28.98 \\
5-152\end{array}$ \\
\hline & Female & $\begin{array}{c}10.33 \pm 6.5 \\
1-18\end{array}$ & $\begin{array}{c}129.5 \pm 35.8 \\
55-185\end{array}$ & $\begin{array}{c}34.8 \pm 20.2 \\
6-73\end{array}$ \\
\hline \multirow[t]{2}{*}{ Abdomen } & Male & $\begin{array}{c}9.6 \pm 6 \\
1-18\end{array}$ & $\begin{array}{c}129.1 \pm 54.9 \\
36-618\end{array}$ & $\begin{array}{c}35.29 \pm 24.82 \\
3-160\end{array}$ \\
\hline & Female & $\begin{array}{c}11.24 \pm 5.9 \\
1-18\end{array}$ & $\begin{array}{c}133.8 \pm 34.1 \\
34-180\end{array}$ & $\begin{array}{c}37.2 \pm 19.3 \\
6-75\end{array}$ \\
\hline \multirow[t]{2}{*}{ Pelvis } & Male & $\begin{array}{c}10.37 \pm 6.4 \\
1-18 \\
\end{array}$ & $\begin{array}{c}130.18 \pm 38.7 \\
60-185 \\
\end{array}$ & $\begin{array}{c}38.15 \pm 24.6 \\
8-76\end{array}$ \\
\hline & Female & $\begin{array}{c}11.4 \pm 6.2 \\
1-18 \\
\end{array}$ & $\begin{array}{c}135.3 \pm 35.5 \\
15-178\end{array}$ & $\begin{array}{c}38 \pm 20.18 \\
7-74\end{array}$ \\
\hline
\end{tabular}

Table-3: Show radiation dose parameters per exam for male and female

\begin{tabular}{|c|c|c|c|c|c|c|}
\hline \multirow{2}{*}{ Exam } & Gender & Tube Voltage & Tube Current & $\begin{array}{c}\text { CTDIvol } \\
\boldsymbol{m G y}\end{array}$ & $\begin{array}{c}\text { DLP } \\
\boldsymbol{m G y . c m}\end{array}$ & $\begin{array}{c}\text { ED } \\
\boldsymbol{m S v}\end{array}$ \\
\hline \multirow{2}{*}{ Brain } & Male & $120.60 \pm 6.7$ & $220 \pm 150$ & $48.62 \pm 25.7$ & $944.7 \pm 654$ & $1.98 \pm 1.37$ \\
& & $100-130$ & $11-721$ & $1.6-99.5$ & $52-3049$ & $0.11-6.40$ \\
\cline { 2 - 7 } & \multirow{2}{*}{ Female } & $119.5 \pm 6.6$ & $218.55 \pm 136.4$ & $52.99 \pm 42.6$ & $890.8 \pm 601.2$ & $1.87 \pm 1.26$ \\
& & $110-130$ & $29-490$ & $1.9-467.9$ & $7.4-2449$ & $0.02-5.14$ \\
\hline \multirow{2}{*}{ Chest } & \multirow{2}{*}{ Male } & $119.2 \pm 5.8$ & $120.6 \pm 85.2$ & $7.4 \pm 5.85$ & $255.2 \pm 203$ & $3.57 \pm 2.84$ \\
& & $100-130$ & $18-544$ & $1-38$ & $26.5-821$ & $0.37-11.5$ \\
\cline { 2 - 7 } & \multirow{2}{*}{ Female } & $120.3 \pm 6.4$ & $127.17 \pm 96.12$ & $8.2 \pm 6.6$ & $256.8 \pm 260$ & $3.6 \pm 3.64$ \\
& & $100-130$ & $17-350$ & $0.6-31.3$ & $10.9-1205.9$ & $0.15-16.88$ \\
\hline \multirow{2}{*}{ Pelvis } & \multirow{2}{*}{ Male } & $119.1 \pm 54.9$ & $126.8 \pm 112.5$ & $8.62 \pm 8.4$ & $350.09 \pm 385.8$ & $5.25 \pm 5.79$ \\
& & $80-130$ & $19-339$ & $0.9-27.6$ & $17-1508$ & $0.03-22.63$ \\
\cline { 2 - 7 } & \multirow{2}{*}{ Memale } & $119.76 \pm 8.2$ & $160.1 \pm 121.2$ & $10 \pm 9.6$ & $408.76 \pm 417.9$ & $6.12 \pm 6.26$ \\
& & $80-130$ & $22-360$ & $1-49$ & $39.2-1447.3$ & $0.59-21.71$ \\
\cline { 2 - 7 } & \multirow{2}{*}{ Female } & $120.29 \pm 6.7$ & $146.5 \pm 144$ & $13.79 \pm 20.7$ & $536 \pm 940$ & $8 \pm 14.1$ \\
& & $110-130$ & $15-490$ & $1-75$ & $1.3-4548.7$ & $0.02-68.23$ \\
\hline
\end{tabular}

Table-4: Show statistical parameters of effective dose for all patients

\begin{tabular}{|c|c|c|c|c|c|c|c|}
\hline Exam & Gender & Mean & STD & Median & Min & Max & 3d Quartile \\
\hline \multirow{3}{*}{ Brain } & Male & 1.98 & 1.37 & 1.42 & 0.11 & 6.40 & 3.28 \\
\cline { 2 - 8 } & Female & 1.87 & 1.26 & 1.36 & 0.02 & 5.14 & 2.99 \\
\hline \multirow{2}{*}{ Chest } & Male & 3.57 & 2.84 & 2.89 & 0.37 & 11.49 & 4.76 \\
\cline { 2 - 8 } & Female & 3.59 & 3.64 & 2.60 & 0.15 & 16.88 & 4.39 \\
\hline \multirow{2}{*}{ Abdomen } & Male & 5.25 & 5.79 & 2.70 & 0.03 & 22.63 & 6.52 \\
\cline { 2 - 8 } & Female & 6.13 & 6.26 & 3.34 & 0.59 & 21.71 & 6.48 \\
\hline \multirow{2}{*}{ Pelvis } & Male & 8.04 & 14.11 & 2.40 & 0.02 & 68.23 & 7.04 \\
\cline { 2 - 8 } & Female & 6.23 & 9.73 & 2.93 & 0.02 & 52.23 & 6.53 \\
\hline
\end{tabular}

CTA examinations in adult patients have contributed greatly to the diagnosis of different diseases; however, the radiation exposure to the patient is significantly higher compared with other radiologic examinations. An overview of patient information and scan parameters used for Computed Tomography CT At 
five different hospitals in Khartoum state - Sudan, is presented Table 1. show the gender distributed according to selected CT scan were the total number of patients was 855 patients, approximately $45 \%$ of the patient for brain (386; 233 males and 153 female), about $22 \%$ for chest $(191 ; 121$ males and 70 female), about $10 \%$ for CT abdomen (90; 44 males and 46 female) and $21 \%$ for pelvis CT (188; 102 males and 86 female) with total number of male and female 500 and 355 respectively.

Mean, and standard deviation, Maximum and minimum, of demographic information for all patients age years, weight $\mathrm{kg}$ and high $\mathrm{cm}$, and for male and female patients separately. Shown in table 2. Table 3 . Show radiation dose parameters tube voltage $(\mathrm{kV})$, tube current -time (mAs), CTDIvol (mGy), DLP (mGy.cm) and effective dose per $\mathrm{mSv}$ for all patients and for male and female patients separately.

The effective dose consider the important unit of patients dose, here we present the statical parameters for effective dose shown as mean, median, standard deviation, minimum, maximum and third quartile for all patients and for male and female patients separately in table 4 . The effective dose found $1.93 \mathrm{mSv}$ for brain (1.98 $\mathrm{mSv}$ for male and $1.87 \mathrm{mSv}$ for female), in CT Chest the effective dose was $3.58 \mathrm{mSv}$ ( $3.57 \mathrm{mSv}$ for male and $3.59 \mathrm{mSv}$ for female), for abdomen was 5.69 $\mathrm{mSv}(5.25 \mathrm{mSv}$ for male and $6.13 \mathrm{mSv}$ for female) and for pelvis the $\mathrm{E}$ found $7.14 \mathrm{mSv}(8.04 \mathrm{mSv}$ for male and $6.23 \mathrm{mSv}$ for female).

\section{CONCLUSION}

Estimation of radiation effective dose for pediatric from CT procedures, in five main hospitals in Khartoum state-Sudan, total number of patients included in this study were 855 patients, the effective dose was slightly variety for patients according to gender and patient's age, Different technician's habits and lack of training among hospital staff responsible from these variations. Dose estimation for patients according to gender has been found.

The effective dose found $1.93 \mathrm{mSv}$ for brain (1.98 $\mathrm{mSv}$ for male and $1.87 \mathrm{mSv}$ for female), in CT Chest the effective dose was $3.58 \mathrm{mSv}$ (3.57 mSv for male and $3.59 \mathrm{mSv}$ for female), for abdomen was 5.69 $\mathrm{mSv}(5.25 \mathrm{mSv}$ for male and $6.13 \mathrm{mSv}$ for female) and for pelvis the $\mathrm{E}$ found $7.14 \mathrm{mSv}(8.04 \mathrm{mSv}$ for male and $6.23 \mathrm{mSv}$ for female).

The main contributor for this difference between the hospitals because the use of a larger scan length due to lack of proper training to CT operators in Sudan.

\section{REFERENCES}

1. Brenner DJ, Hall EJ. Computed tomography - an increasing source of radiation exposure. New
England Journal of Medicine. 2007 Nov 29;357(22):2277-84.

2. Redberg RF, Smith-Bindman R. We are giving ourselves cancer. New York Times. 2014 Jan 30;30(1).

3. Karimi-Afshar L, Riahi Alam N, Ay M, Allahverdi M, Alahverdi Purfallah T, Hashemi H, Farahani A, Reafie B, Bakhteiari M. Evaluation of MRI-based Polymer Gel Dosimetry for Measurement of CT Dose Index (CTDI) on 64 slices CT Scanners. Iranian Journal of Medical Physics. 2009 Jun $1 ; 6(2): 59-70$.

4. United Nations. Scientific Committee on the Effects of Atomic Radiation. Effects of ionizing radiation: report to the General Assembly, with scientific annexes. United Nations Publications; 2008.

5. International Atomic Energy Agency (IAEA). Protection of patients in diagnostic and intervention radiology, nuclear medicine and radiotherapy. Proceeding of International Conference, Malaga, Spain, 26-30 March 2001; Vienna.

6. Klement AW. Estimates of Ionizing Radiation Doses in the United States, 1960-2000. US Environmental Protection Agency, Office of Radiation Programs, Division of Criteria and Standards; 1972.

7. Linton OW, Mettler Jr FA. National conference on dose reduction in $\mathrm{CT}$, with an emphasis on pediatric patients. American Journal of Roentgenology. 2003 Aug;181(2):321-9.

8. The US. Food and Drug Administration. RadiationEmitting Products Computed Tomography (CT). Available at: http:// www.fda.gov/cdrh/ct/risks.html. Published 2002. Last updated July 27, 2009. [Accessed October 17, 2009].

9. Semelka RC, Armao DM, Elias J, Huda W. Imaging strategies to reduce the risk of radiation in CT studies, including selective substitution with MRI. Journal of Magnetic Resonance Imaging: an Official Journal of the International Society for Magnetic Resonance in Medicine. 2007 May;25(5):900-9.

10. Huda W. Radiation dosimetry in diagnostic radiology. AJR Am J Roentgenol. 1997;169:14871488.

11. McNitt-Gray MF. AAPM/RSNA Physics tutorial for residents: topics in CT. Radiation dose in CT. Radiographics. 2002; 22:1541-1553.

12. Huda W, Ogden KM, Khorasani MR. Converting CT dose length product (DLP) to eff ective dose. Radiology. 2008;248: 995-1003.

13. International Commission on Radiological Protection Publication 103. The 2007 Recommendations of the ICRP. Ann ICRP. 2007;37:2-4.

14. National Research Council Committee to Assess Health Risks from Exposures to Low Level of Ionizing Radiation NRC. Health Risks From 
Exposure to Low Levels of Ionizing Radiation: BEIR VII, Phase 1. Washington, DC: National Academies Press; 2005.

15. Hall E. Radiobiology for the Radiologist. Philadelphia, PA: Lippincott Williams \& Wilkins; 2006.

16. Brenner D, Elliston C, Hall E, Berdon W. Estimated risks of radiation-induced fatal cancer from pediatric CT. AJR 2001; 176:289-296

17. Paterson A, Frush DP, Donnelly LF. Helical CT of the body: are settings adjusted for pediatric patients? AJR. 2001; 176:297-301

18. Huda W, Scalzetti EM, Levin G. Technique factors and image quality as functions of patient weight at abdominal CT. Radiology. 2000; 217:430-435

19. Donnelly LF, Emery KH, Brody AS, Laor T, Gylys-Morin VM, Anton CG, Thomas SR, Frush DP. Minimizing radiation dose for pediatric body applications of single-detector helical CT: strategies at a large children's hospital. American Journal of Roentgenology. 2001 Feb;176(2):303-6.

20. Judy PF. Comment on "In X-ray computed tomography, technique factors should be selected appropriate to patient size." Med Phys. 2001; 28:2389

21. International Commission on Radiological Protection. Radiation protection in medicine. ICRP Publication 105. Ann. ICRP 37(1-63) (2007).

22. Lee CI, Haims AH, Monico EP, Brink JA, Forman HP. Diagnostic CT scans: assessment of patient, physician, and radiologist awareness of radiation dose and possible risks. Radiology. 2004 May;231(2):393-8.

23. Li X, Samei E, Segars WP, Sturgeon GM, Colsher JG, Toncheva G, Yoshizumi TT, Frush DP. Patient- specific radiation dose and cancer risk estimation in CT: Part II. Application to patients. Medical physics. 2011 Jan;38(1):408-19.

24. Huda W, Mettler FA. Volume CT dose index and dose-length product displayed during CT: what good are they?. Radiology. 2011 Jan;258(1):23642 .
25. McNitt-Gray MF. AAPM/RSNA physics tutorial for residents: topics in CT: radiation dose in CT. Radiographics. 2002 Nov;22(6):1541-53.

26. Vennart J. The 1990 recommendations of the international Commission on radiological protection. Journal of Radiological Protection. 1991 Sep;11(3):199.

27. Recommendations of the International Commission on Radiological Protection: Adopted January 17, 1977. International Commission on Radiological Protection publication 26. Oxford, England: Pergamon, 1977.

28. Exposures of the US population from diagnostic medical radiation: recommendations of the National Council on Radiological Protection and Measurements. National Council on Radiological Protection and Measurements report no. 100. Bethesda, Md: National Council on Radiological Protection and Measurements, 1989.

29. Radiation doses to patients from radiopharmaceuticals. International Commission on Radiological Protection publication no. 53. In: Annals of the ICRP 18 (nos. 1-4). Oxford, England: Pergamon; 1987.

30. United Nations Scientific Committee on the Effects of Atomic Radiation. Sources and effects of ionizing radiation: UNSCEAR 1993 report to the General Assembly. New York, NY: United Nations; 1993.

31. Castronovo FP. An attempt to standardize the radiodiagnostic risk statement in an institutional review board consent form. Invest Radiol. 1993; 28:533-538.

32. Ridely. CT dose reporting challenged by current indicators. 2012; [online], www.auntminnie.com. [accessed on 13/3/2013].

33. International Commission on Radiological Protection, ICRP 2007 Managing Patient Dose in Multi-Detector Computed Tomography(MDCT) ICRP Publication 102 Ann ICRP 37(1). 